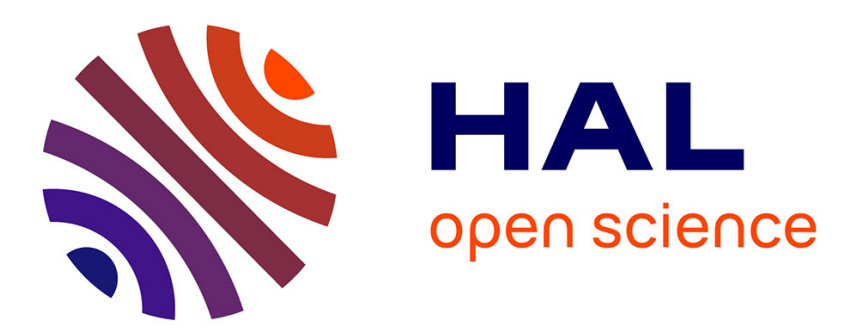

\title{
Characterization of the nano-bio interaction between metallic oxide nanomaterials and freshwater microalgae using flow cytometry
}

Andrea Rivero Arze, Nicolas Manier, Amelie Chatel, Catherine Mouneyrac

\section{- To cite this version:}

Andrea Rivero Arze, Nicolas Manier, Amelie Chatel, Catherine Mouneyrac. Characterization of the nano-bio interaction between metallic oxide nanomaterials and freshwater microalgae using flow cytometry. Nanotoxicology, 2020, 14 (8), pp.1082-1095. 10.1080/17435390.2020.1808106 . ineris-03318327

\section{HAL Id: ineris-03318327}

https://hal-ineris.archives-ouvertes.fr/ineris-03318327

Submitted on 9 Aug 2021

HAL is a multi-disciplinary open access archive for the deposit and dissemination of scientific research documents, whether they are published or not. The documents may come from teaching and research institutions in France or abroad, or from public or private research centers.
L'archive ouverte pluridisciplinaire HAL, est destinée au dépôt et à la diffusion de documents scientifiques de niveau recherche, publiés ou non, émanant des établissements d'enseignement et de recherche français ou étrangers, des laboratoires publics ou privés. 


\section{Characterization of the nano-bio interaction between metallic oxide nanomaterials and freshwater microalgae using flow cytometry}

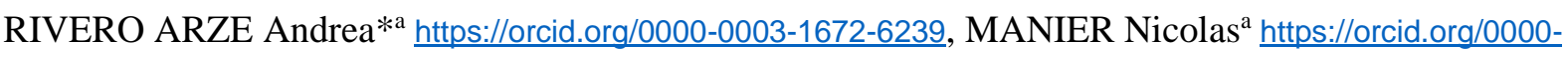
0003-3873-6657, CHATEL Amélie ${ }^{\mathrm{b}}$ https://orcid.org/0000-0003-2245-0216, MOUNEYRAC Catherine ${ }^{\mathrm{b}}$ https://orcid.org/0000-0003-3769-0386

${ }^{a}$ French National Institute for Industrial Environment and Risks (INERIS), Parc Technologique ALATA, BP2, 60550 Verneuil en Halatte, FRANCE

b Catholic University of the West (UCO), Laboratoire Mer, Molécules, Santé (MMS, EA 2160); 3 place André Leroy, 49008 Angers, FRANCE

*Address correspondence to: Andrea.RIVERO-ARZE@ineris.fr 


\title{
Characterization of the nano-bio interaction between metallic oxide nanomaterials and freshwater microalgae using flow cytometry
}

\begin{abstract}
Since nanomaterials (NMs) are particulate contaminants, their first contact with organisms is a physical encounter ruled by physic-chemical processes that can determinate the potential NMs accumulation, toxicity and trophic transfer. Freshwater ecosystems often become a final depository for NMs, so they can get in contact with the biota, especially primary organisms as algae. There are almost none comparative studies of this interaction using various NMs in the same conditions. This work identifies, analyzes and compares the algae-NMs interaction by flow cytometry after a short-term contact test in which three freshwater algae (Raphidocelis subcapitata, Desmodesmus subspicatus and Chlorella vulgaris) interact individually with a set of twelve metallic oxide NMs. Dose-response profiles and differences in the algae-NMs interaction were found according to each algae species $(C$. vulgaris had the most affinity, starting the interaction from $0.5 \mathrm{mg} / \mathrm{L}$ and $D$. subspicatus had the less affinity starting at $5 \mathrm{mg} / \mathrm{L}$ ). Flow cytometry results were confirmed by optical microscopy. Some NMs characteristics were identified as key-factors that govern the algae-NMs interaction: NMs composition (no interaction for $\mathrm{SiO}_{2} \mathrm{NMs}$ ), surface electric charge (higher interaction for the positively charged NMs and lower interaction for the negatively charged ones) and crystalline form (for $\mathrm{TiO}_{2} \mathrm{NMs}$ ). The presented method can be useful for a rapid determination of the interaction between free cells organisms as microalgae and (nano)particulate substances.
\end{abstract}

\section{Keywords}

Freshwater microalgae, nanomaterials, flow cytometry, nano-bio interaction, contact test. 


\section{Introduction}

Nanotechnology has experienced a rapid development due to the various applications of nanomaterials (NMs). With the increasing production and use of NMs, the possible release into natural continental or marine aquatic ecosystems became a great concern for the scientific community (Ju-Nam and Lead, 2008). Besides the environmental exposure, determining and understanding the potential effects induced by these NMs continues to raise questions. One of the singularities of these substances is their duality of action, both physical (ex. adhesion, adsorption, physical alteration of tissues) and chemical. This physical effect, caused by the peculiarity of NMs to have a confined physical shape, can be defined as a mechanical effect which is not directly associated to a chemical reaction, especially for MNs that are poorly (or not) soluble in water (Wang et al., 2016) (Skjolding et al., 2016) (Sørensen et al., 2016).

Several authors have put forward the necessity to study this physical interaction in parallel to chemical and toxicological effects. For example, it can be reported phenomenon such as adsorption, adhesion, abrasion or obstruction of organs like fish gills, gut cells, filter organs of filter feeders or suspensivor species as well as alteration of swimming organs of microinvertebrates (Hansen et al., 2017) (Angel et al., 2015) (Campos et al., 2013) (Dabrunz et al., 2011) (Rodea-Palomares et al., 2011) (Vallotton et al., 2015). The interaction at the nano-bio interfaces is considered as a prerequisite and of vital importance to the nanotoxicity, but this kind of studies are not yet very present in nowadays research (Ma and Lin, 2012). Determining the interaction between MNs and organisms is also crucial for estimating the potentiality of a NM to accumulate and be transferred through the trophic chain as their availability for higher trophic level will depend on their affinity with the prey organism (Rosendal Tangaa et al., 2016). 
A recurrent problem in the study of NMs ecotoxicity is that, the ecotoxicological tests for NMs are being carried on based in the available test guideline, since a specific regulatory framework for NMs does not yet exists (Arts et al., 2016). This lack of consideration may generate incomplete data and disregard some critical information. A categorization approach can facilitate regulatory decision-making in the future. While some proposals of categorization based on the physico-chemical properties of NMs have been presented (Hund-Rinke et al., 2018), tools and methods are still needed to allow rapid material categorization according to human health and environmental risk potential.

Regarding the study of NMs ecotoxicology, many organisms are being studied, and for the freshwater ecosystems, algae is the most common representative of primary producers mainly due to their ecological value constituting the basis of aquatic trophic chains (Ribeiro et al., 2015), their sensitivity to toxicants and easy culturing methods (Wang et al., 2019). Several authors have already reported the potential interaction between NMs and freshwater microalgae (Manier et al., 2013) (Aruoja et al., 2009) (Booth et al., 2015) (Hartmann et al., 2010) (Hartmann et al., 2012) and it has already been showed (by microscopy observations) that NMs can adhere to the cell walls (Renault et al., 2008) (Van Hoecke et al., 2008). Some related adverse effects are described as: a diminution of light access due to a shading effect causing nutrient intake limitations (Rogers et al., 2010), severe membrane damage, thickening of the extracellular polymeric substances layer, and it has also been demonstrated that NMs can be internalized, transformed and stored in the cell causing ultra-structural damages and important toxic effects as oxidative stress (Zhao et al., 2016). Also, the interactions of NMs with proteins and polysaccharides of the cell wall seem to play an important role in NMs uptake (Slaveykova et al., 2020).

The NMs-organism interaction has been studied using different methods, however, it is still a big challenge to correctly and precisely analyze the nano-bio interfaces and interactions. The 
visual methods, including many types of microscopy, allow to observe the NMs morphology, distribution and association with organisms (Vallotton et al., 2015) (Pakrashi et al., 2013), but they are rarely quantifiable. Adsorption experiments with analytics as ICP dosing can be performed to study this association, but it is difficult to determine if the analyzed compound corresponds to a nanoparticulate form or ionic form (Ma and Lin, 2012). Other authors have calculated the attachment efficiency of NMs to microorganisms (Ma et al., 2015) (Nolte et al., 2017) (Pajerski et al., 2019), but these studies are still strongly based on models and they are representative only for certain conditions. An alternative method to analyze microalgae-NMs interaction can be flow cytometry, this method measures optical and fluorescence characteristics of single units through a flow; the units can be particles, cells or microorganisms; their physical properties, such as size (represented by forward angle light scatter) and internal complexity (represented by right-angle scatter) can discriminate certain populations (Brown and Wittwer, 2000). It has already been used to identify and evaluate the uptake of NMs in mammalian cells (Suzuki et al., 2007) (Zucker et al., 2010), bacteria (Kumar et al., 2011) and for microalgae by (Manier et al., 2013) following fluorescence (FL1) vs. cell granularity (SSC) modification.

Acquiring key data at the nano-bio interface is crucial in understanding the relationship between the physicochemical properties of nanomaterials and their related toxicity, therefore quantitative analysis is always necessary in the quest to understand nanotoxicity (He et al., 2015). There are studies that have concluded that the toxicity of NMs towards algae occurred through the surface interactions (Hoecke et al., 2008), that this toxicity can be dependent of NMs characteristics as shape, size and surface chemistry (Monikh et al., 2020) and it is also caused by the algae-NMs heteroagglomeration (Joonas et al., 2019). However, a gap still exists for a method that can identify, quantify and compare this algae-NMs interaction and at the best of our knowledge, while some work concerning NMs and algae interaction exists, a 
comparative and systematic study testing a large set of various NMs and several microalgae species does not yet exist. Such kind of work can be helpful to better understand the physical and biological parameters involved in the NMs-algae interaction.

In that context, we present a novel method, that includes a short time contact test and an analysis via flow cytometry with the main objective of identify and compare the interaction between a set of metal oxide NMs with three different freshwater microalgae. Therefore, investigate the algae physiological parameters and MNs physic-chemical characteristics that can influence this interaction.

\section{Materials and Methods}

\subsection{Freshwater algae culture}

All the freshwater green algae used in the present study came from the Culture Collection of Algae and Protozoa (CCAP), Raphidocelis subcapitata strain CCAP278/4, Desmodesmus subspicatus strain CCAP276/22 and Chlorella vulgaris strain CCAP211/11B. The algae were cultivated in the laboratory according to the OECD201 test guideline (OECD, 2011). The tests were carried on with algae pre-cultures consisting of an inoculum of $3 \pm 1$ days in the OECD algae growth media. All algae were kept in constant agitation $(110 \mathrm{rpm})$ at a temperature of $\left(22^{\circ} \mathrm{C} \pm 2\right)$ and under artificial lightening (5500-6000 lux).

\subsection{Nanomaterials}

For the present study, the majority of the NMs that have been chosen came from the JRC Nanomaterial Repository and are considered as reference nanomaterials as they are well known and characterized (European Commission Joint Research Centre, 2014) (European Commission Joint Research Centre, 2013) (European Commission Joint Research Centre, 2012). The set is composed of 6 Titanium dioxide $\left(\mathrm{TiO}_{2}\right)$ NMs (NM100, NM101, NM102, NM103, NM104, 
NM105)(European Commission Joint Research Centre, 2014), 1 Zinc oxide (ZnO) NMs (NM110)(European Commission Joint Research Centre, 2012) and 3 Silica dioxide $\left(\mathrm{SiO}_{2}\right) \mathrm{NMs}$ (NM200, NM202, NM204)(European Commission Joint Research Centre, 2013). Finally, the 2 Cerium oxide $\left(\mathrm{CeO}_{2}\right)$ NMs tested were named for the present work in relation of their diameter size as $\mathrm{CeO}_{2}<10 \mathrm{~nm}\left(\mathrm{NanoBYK}^{\circledR}\right)$ and $\mathrm{CeO}_{2}<25 \mathrm{~nm}$ (Sigma Aldrich nanoCeO ${ }_{2}$ ). Their main characteristics are detailed in the supplementary data section.

\subsection{NMs preparation and characterization}

Each NMs stock suspension was prepared following the dispersion protocol from the NANOGENOTOX Program (Keld, 2014), without using the bovine serum albumin nor the ethanol. Briefly, $38.4 \mathrm{mg}$ of NMs were dispersed in $15 \mathrm{~mL}$ of MiliQ water. First, a phase of prewetting is carried on in order to well hydrate the powder using some drops of the MiliQ water and revolving gently. After this step the rest of the ultrapure water volume was added. The suspension is then sonicated with a Vibra-Cell ${ }^{\mathrm{TM}}$ (VCX 750, Sonics) sonicator during 16 minutes at $20 \%$ amplitude in an ice bath, delivering approximatively $7056 \pm 103 \mathrm{~J}$ or a total delivered acoustic power of $7.35 \pm 0.05$ Watt (Booth and Keld, 2015). Working suspensions at $100 \mathrm{mg} / \mathrm{L}$ were prepared from the stock suspensions and they were diluted using the OECD freshwater algae media in order to provide the NMs the characteristics of the interaction test.

All the NMs suspensions (stock and working suspensions) were characterized using a Dynamic Light Scattering (DLS; NanoZS, Malvern Instruments ${ }^{\circledR}$ ). The NMs hydrodynamic diameter was measured both in ultrapure water and in algae media with a non-invasive back scatter detection at $173^{\circ}$ with a $\mathrm{He}-\mathrm{Ne}$ laser $(\lambda=633 \mathrm{~nm})$ as light. The aggregate sizes were determined by the Non-Negative Least Squares (NNLS) analysis method at $25^{\circ} \mathrm{C}$, after an equilibration time of 60 s. Each measurement is an average of 13 runs of 10 seconds. The Zeta potential was measured with a Zetasizer (NanoZS, Malvern Instruments ${ }^{\circledR}$ ) and calculated using the 
Smoluchowski approximation. All size and zeta potential measurements were done in triplicates.

\subsection{Algae-NMs contact test and flow cytometry analysis}

Each of the three algae (R. subcapitata, D. subspicatus and C. vulgaris) were put in contact with each NMs suspension during $15 \mathrm{~min}$ in a glass vial with constant stirring (300 rpm; using a 1,5 cm diameter magnetic stirring rod) as described by (Manier et al., 2016). The optimal algae concentration for this test was defined to be $5^{*} 10^{5}$ cell $/ \mathrm{mL}$ for all samples. All vials were put in a $23 \pm 2^{\circ} \mathrm{C}$ water bath, with an artificial lightening (4000-5000 lux, using $36 \mathrm{~W} / 840,3350$ lumens cool white tubes). To obtain a dose-response curve, 10 different concentrations were tested as follows, $0.1 ; 0.5 ; 1 ; 2.5 ; 5 ; 7.5 ; 10 ; 12.5 ; 25$ and $50 \mathrm{mg} / \mathrm{L}$. The dilutions were prepared starting from the working suspensions and using the OECD freshwater algae media. The NMs suspension was added to the algae in the media suspension to obtain an immediate interaction with the algae. Each algae-NMs contact test was repeated independently 3 times and each condition had 2-3 intern replicates.

All samples were analyzed using a CyAn ${ }^{\mathrm{TM}}$ ADP High-Performance Flow Cytometer (Beckman coulter), where the fluorescence (FL1 Log) and the granularity or cell complexity (side scattering logarithm, SS Log) were measured. For each algae-NMs interaction analysis, a control population sample of algae without NMs, was analyzed and a profile of the control population has been determined. The displacement of the cytogram outline of the test samples $($ algae $+\mathrm{NMs}$ ) was compared to the algae control population profile to find the percentage of algae with modified granularity (Fig. 1). The flow cytometry data was analyzed using Flowing Software (version 2.5.1). Further details on the method are provided in Supplementary Data.

\subsection{Optical Microscopy analysis}


During the interaction contact test, the samples were observed using an optical microscope (OLYMPUS CX41, Upright Microscope) coupled to a camera (Olympus U-CMAD3 Lens, Japan) and photos were taken at 10x, 20x and 40x objectives for the 1, 5, 10 and $50 \mathrm{mg} / \mathrm{L}$ concentration for all the tested NMs in contact with $R$. subcapitata. The photos were analyzed using Saisam software (version 10.5.0 - MICROVISION Instruments).

\subsection{Interaction kinetics}

The freshwater algae - NMs interaction was analyzed during two hours with samplings at 15 minutes, 1 hour and 2 hours in order to study if there were differences within the exposure time at this scale. The algae used for this test was $R$. subcapitata. The same contact test was used as before explained and the same cytometry analysis was carried on.

\subsection{Statistical analysis}

All data were analyzed with $\mathrm{R}$ software (version 3.6.1). A preliminary test of normality was carried on using Shapiro-Wilk's test which result significant, so a Kruskal-Wallis test for nonparametrical data was applied and the Bonferroni correction for the post-hoc Wilcoxon pairwise comparison test was used (significance of $\mathrm{p}<0.05$ ).

\section{Results}

\subsection{NMs characterization}

The applied NMs dispersion protocol has allowed to obtain homogenic NMs suspensions with different sizes of agglomerates. Consequently, all the stock suspensions in ultrapure water and in reconstituted water for algal interaction test have been characterized for their hydrodynamic diameter and zêta potential. The results are summarized in Table 1. Agglomerate sizes for $\mathrm{TiO}_{2}$ range from $168 \mathrm{~nm}$ (NM103) to larger hydrodynamic sizes that are above 1 $\mu \mathrm{m}$ (NM 102 and $\mathrm{NM}$ 105). By comparison, $\mathrm{SiO}_{2} \mathrm{NMs}$ diameters in ultrapure water ranged from $175 \mathrm{~nm}$ 
(NM202) to $250 \mathrm{~nm}$ (NM200). The smallest NMs size is $\mathrm{CeO}_{2}<10 \mathrm{~nm}$ with $8.8 \pm 3.3 \mathrm{~nm}$. It can be noted that the NMs aggregates diameters increases when passing from the stock solution that is made in ultrapure (Milli- $\mathrm{Q}^{\circledR}$ ) water to the working solution that was made in the algae growth media. For many NMs, the contact with the algae media generates agglomerates with a hydrodynamic diameter bigger than $1000 \mathrm{~nm}$, which are outside the analytic limits of the DLS method and they cannot be measured with precision, so they are just expressed as $>1000 \mathrm{~nm}$ in Table 1. All these suspensions made of large agglomerates (NM102, NM103, NM104, NM105, NM110 and $\mathrm{CeO}_{2}<25 \mathrm{~nm}$ ) have shown the tendency to sediment after a few hours.

The NMs suspensions in ultrapure water are mostly negative except for four NMs that are NM103 (14.0 \pm 1.6$),$ NM104 (16.5 \pm 3.2$), \mathrm{NM} 110(27.1 \pm 1.0)$ and $\mathrm{CeO}_{2}<25 \mathrm{~nm}(43.5 \pm 0.9$ $\mathrm{mV}$ ). It is important to note that the two $\mathrm{CeO}_{2} \mathrm{NMs}$ have different charges, being one negative and the other positive. The three $\mathrm{SiO}_{2} \mathrm{NMs}$ are the most negative of the lot with charges around $-30 \mathrm{mV}$. The tested NMs suspensions in algae growth medium are generally negatively charged, except for NM103 and NM104 who shown a zeta potential of $17.4 \mathrm{mV}$ and $10.3 \mathrm{mV}$, respectively.

\subsection{Algae-NMs interaction}

The interaction between algae and NMs has been determined from the percentage of modified granularity/complexity of algae in comparison with the control population. Dose-response profiles have been obtained for all the tested NMs (figure 2).

The obtained results show that there are differences in the interaction depending on the algae species, where D. subspicatus shows the lowest interaction as the percentage of algae complexity starts to change from $5 \mathrm{mg} / \mathrm{L}$ and it does not reach $100 \%$ at the highest tested concentration for any of the NMs. Meanwhile, C. vulgaris and R. subcapitata starts to increase 
the percentage of modified granularity from $0.5 \mathrm{mg} / \mathrm{L}$ for all the tested $\mathrm{NMs}$ except $\mathrm{SiO}_{2}$ showing that these species can have a higher interaction capability with the tested NMs.

A second run of tests have been carried on with the same concentration range $(0.1$ to $50 \mathrm{mg} / \mathrm{L})$ but using only $R$. subcapitata and increasing the number of replicates (i.e. 3 independent runs with 3 intern replicates each), in order to determine the differences between the different NMs. The results show that the NMs-algae interaction can also be determined by the NMs composition, which at one specific concentration, can foremost allow to discriminate the tested NMs (Comparisons made at $7.5 \mathrm{mg} / \mathrm{L}$ are showed in figure 3.). All the $\mathrm{SiO}_{2} \mathrm{NMs}$ show no interaction at all, the $\mathrm{ZnO} \mathrm{NMs}$ have induced around $20 \%$ of modified granularity, and the $\mathrm{CeO}_{2}$ NMs have showed in one case no interaction and in the other case a low (i.e. $<20 \%$ ) modified granularity. The NMs composition that does not have the same range of response for the tested NMs is the $\mathrm{TiO}_{2}$; the percentage of modified granularity can vary from around $10 \%$ to almost $100 \%$ for the same concentration.

For the $\mathrm{TiO}_{2}$ NMs block, at the intermediate response concentrations (between 5 and $25 \mathrm{mg} / \mathrm{L}$ ), three groups can be distinguished, where the algae-NMs interaction results in either high (more than $60 \%$ ), intermediate (between $20 \%$ and $60 \%$ ) or low (under $20 \%$ ) percentage of modified granularity. The group of lower interaction is constituted by NM100, NM101 and NM102, the group of higher interaction is composed by NM103 and NM104; and NM105 shows an intermediate interaction.

Intending to identify which properties can originate the differences in the algae-NMs interaction, a relation was detected between the percentage of modified granularity data and some of the NMs physico-chemical measures. Neither primary NMs size, nor NMs hydrodynamic diameter in algae media were found to have a correlation whatsoever with the results. However, interestingly, zeta potential correlation showed a tendency for the three tested 
algae, in which the most negatively charged NMs showed less interaction than the most positively charged ones (fig. 4). These data will be further discussed in section 4 .

\subsection{Optical microscopy analysis}

While carrying on the algae-NMs interaction test, pictures of the algal-NMs interaction were captured using an optical microscope (figure 5.) and different types of interaction were observed. These results confirm and complete the flow cytometry interaction determination. NM100 forms an entourage of little NMs agglomerates around each cell of $R$. subcapitata but leaving a slight space as if they don't touch directly and many free algae can be found. The interaction with NM101and NM102 shows that NMs agglomerates attach to some of the algae without any surrounding space but mostly free algae are present. The NMs of NM103 seems to form a layer around the algae and it make them aggregate with other covered algae. In the case of NM104, heteroagglomerates of algae and NMs were formed with an axial size going from a few tens to a few hundreds of micrometers. NM105 have formed heteroagglomerates but algae are not entirely covered nor fully incorporated in the agglomerates. For NM103, NM104 and NM105 there were almost none free algae found.

For the $\mathrm{SiO}_{2} \mathrm{NMs}$ (NM200, NM202 and NM204) only free algae have been seen, no sign of attachment was found at any tested concentration, and the same happened for $\mathrm{CeO}_{2}<10 \mathrm{~nm}$. Finally, for $\mathrm{CeO}_{2}<25 \mathrm{~nm}$ homoagglomerates of $\mathrm{CeO}_{2} \mathrm{NMs}$ can be seen surrounding the algae cells.

\subsection{Interaction kinetics}

In order to follow the evolution of the algae-NMs interaction, a new set of exposure of $R$. subcapitata and the 12 tested NMs was analyzed by flow cytometry; measures were made at three different times of exposure (15 minutes, 1 hour and 2 hours). The obtained results were compared to describe the evolution of the percentage of modified granularity at the three 
measured times of interaction (supplementary data Tables S2 and S3.). The coefficient of variation of the control population's granularity was calculated and found to be $5.6 \% \pm 0.7 \%$. Based on this information, the authors determined the threshold to consider a difference as $10 \%$ of modified granularity $\left(\left|\% \mathrm{f}-\%_{\mathrm{i}}\right| \geq 10 \%\right)$. The data that meet this condition and that is statistically different, is consider as a valid difference.

No significant difference in the interaction between microalgae and the 12 tested NMs was found from 15 minutes up to 1 or 2 hours, at any of the 10 tested concentrations. Except for the $\mathrm{CeO}_{2}<25 \mathrm{~nm}$ at $10,12.5$ and $25 \mathrm{mg} / \mathrm{L}$, where a significant difference was found $(13.1 \%, 13.7 \%$ and $13,5 \%$ respectively) between 15 minutes and 2 hours exposure.

\section{Discussion}

In this work, we studied the primary interaction between NMs and microalgae. This interaction is considered as a key event for the accumulation and further toxic effect on such organisms (Wang et al., 2016). For that purpose, we have used a flow cytometry method coupled with optical microscopy observations. A set of 12 NMs and 3 microalgae species (R. subcapitata, D subspicatus and $C$. vulgaris) were considered, and our analyses tend to determine the parameters that influence this interaction for different algae species or between different NMs. In that sense, some of the principal physico-chemical properties of the tested NMs were analyzed both in ultrapure water and in the algae growth media. As expected, the results of the measures of NMs aggregates hydrodynamic diameter were found to be larger in the algae media by comparison with ultrapure water. These results agree with other studies where algae growth media has been shown to have an effect on NMs aggregation (Oukarroum et al., 2012) as it has been demonstrated that the size of the NMs aggregates can vary depending on the particle concentration, $\mathrm{pH}$, ionic strength, ionic composition and other characteristics of the media (Keller et al., 2010). Also, the NMs surface charges (zêta potentials) are different passing from ultrapure water to the algae media, which can imply a NMs surface modification and/or coating 
degradation for the coated NMs as it has been proved for the $\mathrm{TiO}_{2} \mathrm{NMs}$ (European Commission Joint Research Centre, 2014).

Concerning the contact test with microalgae, dose-response profiles were found for each algaeNMs couples, and D. subspicatus showed the lowest percentage of granularity modification while $C$. vulgaris showed the highest being closely followed by $R$. subcapitata. This phenomenon may be linked to the algae cell wall composition. The algae cell walls represents a complex and related species network of variously modified (glycol)proteins, carbohydrates (cellulose, hemicellulose, pectin) and polysaccharide highly organized in a form of a suprastructure which constitutes the cell microenvironment (Alberts et al., 2002),. In addition, structural proteins are found in various content in most algae cell walls, they are classified as hydroxyproline-rich glycoproteins (HRGP), arabinogalactan proteins (AGP), glycine-rich proteins (GRPs), and proline-rich proteins (PRPs) (Showalter, 1993). Recent work has shown that proteins containing more specifically arginine and proline had a strong adsorption to NMs (Mathé et al., 2013) and C. vulgaris cell wall is rich in prolines (Abo-Shady et al., 1993) which may explain their higher interaction with NMs.

The production of extracellular polymeric substances (EPS), has also a very important role in the attachment of NMs (Adeleye and Keller, 2016), the EPS are complex mixtures composed of proteins, polysaccharides, fats, nucleic acids, and inorganic substances (Sheng et al., 2010). The production of EPS by the genus Chlorella has been particularly studied in what concerns the role of EPS in the nano-bio interaction (Zhou et al., 2016) (Gao et al., 2018); which can also explain the stronger adhesion of the tested NMs at $C$. vulgaris. Additionally, R. subcapitata can produce EPS that have been addressed in the issue of agglomerates formation for particulate pollutants (Gorokhova et al., 2020) this may explain why, contrary to the fact that, $R$. subcapitata has a globally similar cell wall composition as $D$. subspicatus (pecto-cellulosic and 
glycoproteic cell wall) (Domozych et al., 2012), it has demonstrated an interaction behavior with NMs very similar to the one of $C$. vulgaris.

Additionally, differences in the algae-NMs interaction were found depending on the NMs composition, in particular for the silica oxide NMs that did not showed interaction with the microalgae, that could be detected by flow cytometry or by optical microscopy; although other study had shown by electronical microscopy, that $\mathrm{SiO}_{2} \mathrm{NMs}$ can be adsorbed to the surface of R. subcapitata (Van Hoecke et al., 2008).

The differences between the percentage of modified algae between the $\mathrm{TiO}_{2} \mathrm{NMs}$ are correlated with the differences in the crystalline form of the tested $\mathrm{TiO}_{2} \mathrm{NMs}$. Since $\mathrm{TiO}_{2} \mathrm{NMs}$ have two main forms: anatase and rutile (Li et al., 2004), each of these forms presents different properties and therefore, different applications and environmental impacts (Ju-Nam and Lead, 2008). Accordingly, NM100, NM101 and NM102 that show low interaction with algae, have all the anatase crystalline form; NM103 and NM104 have rutile form and they show a high interaction; finally, NM105 that presents an intermediate interaction is composed by both rutile and anatase forms. Anatase forms usually have higher porosity and specific surface area than rutile forms (Viana et al., 2010), but in the case of this work, the affinity of algae is not linked to the NMs with higher specific area.

When looking at the entire set of NMs, a correlation was found, in which the most negatively charged NMs had less interaction with algae and vice-versa, it was also found that the tested microalgae had negatively charged surfaces $(R$. subcapitata $-28.1 \pm 3.0 \mathrm{mV}, D$. subspicatus $18.0 \pm 2.0 \mathrm{mV}$ and $C$. vulgaris $-18.2 \pm 2.4 \mathrm{mV}$ ). The negative charge of algae is a result of the presence of carboxylic, phosphoryl, amine and hydroxyl groups on their cell surface (Hadjoudja et al., 2010), this condition is known to be necessary for the adsorption of essential elements and to prevent aggregation of microalgae cells in suspension (Blasco and Corsi, 2019). Due to this negative charge in the algae surface, attractive forces will be higher with positively charged 
NMs, answering to an electrostatic attraction/repulsion principle, that works for the ionic forms (Taylor et al., 1998), and that has been studied for microalgae and NMs under the Derjaguin, Landau, Verwey and Overbeek (DLVO) principle (Ma et al., 2015) and for bacteria (Pajerski et al., 2019). This electrostatic behavior can also be supported by the fact that mostly no significant difference was found in the algae-NMs interaction at 15 minutes and up to 2 hours implying that the physical contact happens almost instantly.

Although, some authors conclude that the DLVO theory is not enough to explain the algaeNMs interaction in algae media and that it is ruled by more complex principles (Sendra et al., 2017). For example, between the other principles that can define the alga-NMs interaction, we believe the NMs hydrophobicity to be one important characteristic that can also explain the link between the microalgae cell wall and the surface of the NMs. Some authors had already studied and quantified hydrophobicity for some NMs (Valsesia et al., 2018) (Cao et al., 2019) and it would be interesting to include these parameters in further works.. Henceforward, the basis for grouping founded on the interaction of NMs with organisms must be anchored in a combination of several NMs physico-chemical properties and biological endpoints (Hund-Rinke et al., 2018) (Kühnel et al., 2019).

Finally, it is important to note that the algae-NMs contact test analyzed by flow cytometry proposed in the present study does not consider other chemical characteristics as the release of ions from the NMs. For example, it was already reported that for $\mathrm{ZnO} \mathrm{NMs}$, the ecotoxicity is mainly related to the $\mathrm{Zn}^{+}$ion release (Ma et al., 2013). Nevertheless, it can inform on the potential affinity of a NMs toward a microalgae cell and consequently on their potential accumulation and/or "physically-related" toxicity towards these organisms. Another limitation of this method can occur in the case of impossibility at detecting the nanomaterial by flow cytometry, future studies have to be made to analyze this scenario, which is not addressed in the current work because the set of 12 tested nanomaterials were detected by the cytometer. As 
tools and methods that allow a rapid material categorization are needed for regulatory purposes (Godwin et al., 2015) we believe that this test being prepared, ran and analyzed in less than 3 days can be a quick way to screen the initial information for a new NM and can be useful in the context of NMs categorization.

\section{Conclusion}

The present study has developed a short-term contact test to study the interaction between freshwater microalgae and metal oxide NMs using flow cytometry. This method has allowed to determine quantitatively the algae-NMs interaction through the percentage of modified algae granularity in comparison with a control population. In this work we have investigate the interaction between 3 different micro-algae and twelve metal oxide NMs. The flow cytometry results have been confirmed by optical microscopy observations. Dose-response curves in a form of a sigmoid profile were found for each tested algae-NMs couple. The differences between the algae-NMs interaction profiles are found to be determined by the algae species and the NMs characteristics. Regarding the algae species, at any given concentration, $C$. vulgaris presents the highest interaction with NMs in comparison with the other species, being followed by $R$. subcapitata; and finally, by $D$. subspicatus. The NMs characteristics that have showed an influence in this interaction are, from one side, the composition (no detected interaction for $\mathrm{SiO}_{2} \mathrm{NMs}$ ), and from other side, the zeta potential (negatively charged NMs interact less with the algae than the positively charged ones). Furthermore, for the $\mathrm{TiO}_{2} \mathrm{NMs}$, their crystalline form may have a critical role in the algae-NMs interaction since the anatase forms show less interaction than the rutile forms. The influence of other properties, belonging to algae and/or NMs (e.g. Hydrophobicity, other cell wall compositions, marine algae), may be considered in future works in order to deepen the actual understanding of this process.

We believe this method to be useful to study the interaction between free cells organisms and particulate substances. Further work is needed in order to validate the suitability for other 
(nano)particulate substances (pollutants), such as carbon based NMs, organic NMs, (nano)fragments of polymers. 
Acknowledgements: The authors thank the support of the French Ministry for the Ecological and Inclusive Transition. A special recognition is given to Anne Bado-Nilles for the access to the flow cytometry equipment.

Disclaimer of interests: The authors declare that they have no competing interests.

Data availability statement: Data pertaining to this manuscript are deposited in figshare at https://doi.org/10.6084/m9.figshare.12040401.v1 


\section{References}

Abo-Shady, A.M., Mohamed, Y.A., Lasheen, T., 1993. Chemical composition of the cell wall in some green algae species. Biol Plant 35, 629-632. https://doi.org/10.1007/BF02928041

Adeleye, A.S., Keller, A.A., 2016. Interactions between Algal Extracellular Polymeric Substances and Commercial TiO2 Nanoparticles in Aqueous Media. Environ. Sci. Technol. 50, 12258-12265. https://doi.org/10.1021/acs.est.6b03684

Alberts, B., Johnson, A., Lewis, J., Raff, M., Roberts, K., Walter, P., 2002. The Plant Cell Wall. Molecular Biology of the Cell. 4th edition.

Angel, B.M., Vallotton, P., Apte, S.C., 2015. On the mechanism of nanoparticulate $\mathrm{CeO} 2$ toxicity to freshwater algae. Aquatic Toxicology 168, 90-97. https://doi.org/10.1016/j.aquatox.2015.09.015

Arts, J.H.E., Irfan, M.-A., Keene, A.M., Kreiling, R., Lyon, D., Maier, M., Michel, K., Neubauer, N., Petry, T., Sauer, U.G., Warheit, D., Wiench, K., Wohlleben, W., Landsiedel, R., 2016. Case studies putting the decision-making framework for the grouping and testing of nanomaterials (DF4nanoGrouping) into practice. Regulatory Toxicology and Pharmacology 76, 234-261. https://doi.org/10.1016/j.yrtph.2015.11.020

Aruoja, V., Dubourguier, H.-C., Kasemets, K., Kahru, A., 2009. Toxicity of nanoparticles of CuO, ZnO and $\mathrm{TiO} 2$ to microalgae Pseudokirchneriella subcapitata. Science of The Total Environment 407, 1461-1468. https://doi.org/doi: DOI: 10.1016/j.scitotenv.2008.10.053

Blasco, J., Corsi, I., 2019. Ecotoxicology of Nanoparticles in Aquatic Systems. CRC Press. https://doi.org/10.1201/9781315158761

Booth, A., Keld, A.J., 2015. NANoREG D4.12 SOP Probe Sonicator Calibration for ecotoxicological testing.

Booth, A., Størseth, T., Altin, D., Fornara, A., Ahniyaz, A., Jungnickel, H., Laux, P., Luch, A., Sørensen, L., 2015. Freshwater dispersion stability of PAA-stabilised cerium oxide nanoparticles and toxicity towards Pseudokirchneriella subcapitata. Science of The Total Environment 505, 596-605. https://doi.org/10.1016/j.scitotenv.2014.10.010

Brown, M.D., Wittwer, C.T., 2000. Flow cytometry: principles and clinical applications in hematology. Clinical chemistry 46, 1221-1229.

Campos, B., Rivetti, C., Rosenkranz, P., Navas, J.M., Barata, C., 2013. Effects of nanoparticles of TiO2 on food depletion and life-history responses of Daphnia magna. Aquatic Toxicology 130-131, 174-183. https://doi.org/10.1016/j.aquatox.2013.01.005

Cao, Z., Tsai, S.N., Zuo, Y.Y., 2019. An Optical Method for Quantitatively Determining the Surface Free Energy of Micro- and Nanoparticles. Anal. Chem. 91, 12819-12826. https://doi.org/10.1021/acs.analchem.9b02507

Dabrunz, A., Duester, L., Prasse, C., Seitz, F., Rosenfeldt, R., Schilde, C., Schaumann, G.E., Schulz, R., 2011. Biological Surface Coating and Molting Inhibition as Mechanisms of TiO2 Nanoparticle Toxicity in Daphnia magna. PLOS ONE 6, e20112. https://doi.org/10.1371/journal.pone.0020112

Domozych, D.S., Ciancia, M., Fangel, J.U., Mikkelsen, M.D., Ulvskov, P., Willats, W.G.T., 2012. The Cell Walls of Green Algae: A Journey through Evolution and Diversity. Front Plant Sci 3. https://doi.org/10.3389/fpls.2012.00082

European Commission Joint Research Centre, 2014. Titanium Dioxide, NM-100, NM-101, NM-102, NM-103, NM-104, NM-105: Characterisation and Physico-Chemical Properties.

European Commission Joint Research Centre, 2013. Synthetic amorphous silicon dioxide (NM-200, NM-201, NM-202, NM-203, NM-204): characterisation and physico-chemical properties: JRC repository: $\mathrm{NM}$-series of representative manufactured nanomaterials.

European Commission Joint Research Centre, 2012. NM-Series of Representative Manufactured Nanomaterials: Zinc Oxide NM-110, NM-111, NM-112, NM-113 Characterisation and Test Item Preparation. 
Gao, X., Zhou, K., Zhang, L., Yang, K., Lin, D., 2018. Distinct effects of soluble and bound exopolymeric substances on algal bioaccumulation and toxicity of anatase and rutile TiO2 nanoparticles.

Environ. Sci.: Nano 5, 720-729. https://doi.org/10.1039/C7EN01176H

Godwin, H., Nameth, C., Avery, D., Bergeson, L.L., Bernard, D., Beryt, E., Boyes, W., Brown, S., Clippinger, A.J., Cohen, Y., Doa, M., Hendren, C.O., Holden, P., Houck, K., Kane, A.B., Klaessig, F., Kodas, T., Landsiedel, R., Lynch, I., Malloy, T., Miller, M.B., Muller, J., Oberdorster, G., Petersen, E.J., Pleus, R.C., Sayre, P., Stone, V., Sullivan, K.M., Tentschert, J., Wallis, P., Nel, A.E., 2015. Nanomaterial Categorization for Assessing Risk Potential To Facilitate Regulatory Decision-Making. ACS Nano 9, 3409-3417. https://doi.org/10.1021/acsnano.5b00941

Gorokhova, E., Ek, K., Reichelt, S., 2020. Algal growth at environmentally relevant concentrations of suspended solids: implications for microplastic hazard assessment (preprint). Ecology. https://doi.org/10.1101/2020.04.11.036889

Hadjoudja, S., Deluchat, V., Baudu, M., 2010. Cell surface characterisation of Microcystis aeruginosa and Chlorella vulgaris. Journal of Colloid and Interface Science 342, 293-299. https://doi.org/10.1016/j.jcis.2009.10.078

Hansen, S.F., Sørensen, S.N., Skjolding, L.M., Hartmann, N.B., Baun, A., 2017. Revising REACH guidance on information requirements and chemical safety assessment for engineered nanomaterials for aquatic ecotoxicity endpoints: recommendations from the EnvNano project. Environ Sci Eur 29, 14. https://doi.org/10.1186/s12302-017-0111-3

Hartmann, N.B., Engelbrekt, C., Zhang, J., Ulstrup, J., Kusk, K.O., Baun, A., 2012. The challenges of testing metal and metal oxide nanoparticles in algal bioassays: titanium dioxide and gold nanoparticles as case studies. Nanotoxicology 7, 1082-1094. https://doi.org/10.3109/17435390.2012.710657

Hartmann, N.B., Von der Kammer, F., Hofmann, T., Baalousha, M., Ottofuelling, S., Baun, A., 2010. Algal testing of titanium dioxide nanoparticles--Testing considerations, inhibitory effects and modification of cadmium bioavailability. Toxicology 269, 190-197. https://doi.org/doi: DOI: 10.1016/j.tox.2009.08.008

He, X., Aker, W.G., Fu, P.P., Hwang, H.-M., 2015. Toxicity of engineered metal oxide nanomaterials mediated by nano-bio-eco-interactions: a review and perspective. Environ. Sci.: Nano 2, 564-582. https://doi.org/10.1039/C5EN00094G

Hoecke, K.V., Schamphelaere, K.A.C.D., Meeren, P.V. der, Lcucas, S., Janssen, C.R., 2008. Ecotoxicity of silica nanoparticles to the green alga pseudokirchneriella subcapitata: Importance of surface area. Environmental Toxicology and Chemistry 27, 1948-1957. https://doi.org/10.1897/07-634.1

Hund-Rinke, K., Schlich, K., Kühnel, D., Hellack, B., Kaminski, H., Nickel, C., 2018. Grouping concept for metal and metal oxide nanomaterials with regard to their ecotoxicological effects on algae, daphnids and fish embryos. Nanolmpact 9, 52-60. https://doi.org/10.1016/j.impact.2017.10.003

Joonas, E., Aruoja, V., Olli, K., Kahru, A., 2019. Environmental safety data on CuO and TiO2 nanoparticles for multiple algal species in natural water: Filling the data gaps for risk assessment. Science of The Total Environment 647, 973-980. https://doi.org/10.1016/j.scitotenv.2018.07.446

Ju-Nam, Y., Lead, J.R., 2008. Manufactured nanoparticles: An overview of their chemistry, interactions and potential environmental implications. Science of The Total Environment 400, 396-414. https://doi.org/10.1016/j.scitotenv.2008.06.042

Keld, A.J., 2014. The NANOGENOTOX dispersion protocol for NANoREG.

Keller, A.A., Wang, H., Zhou, D., Lenihan, H.S., Cherr, G., Cardinale, B.J., Miller, R., Ji, Z., 2010. Stability and Aggregation of Metal Oxide Nanoparticles in Natural Aqueous Matrices. Environmental Science \& Technology 44, 1962-1967. https://doi.org/doi: 10.1021/es902987d

Kühnel, D., Nickel, C., Hellack, B., van der Zalm, E., Kussatz, C., Herrchen, M., Meisterjahn, B., HundRinke, K., 2019. Closing gaps for environmental risk screening of engineered nanomaterials. Nanolmpact 15, 100173. https://doi.org/10.1016/j.impact.2019.100173 
Kumar, A., Pandey, A.K., Singh, S., Shanker, R., Dhawan, A., 2011. A flow cytometric method to assess nanoparticle uptake in bacteria. Cytometry Part A 79A, 707-712. https://doi.org/10.1002/cyto.a.21085

Li, Y., Lee, N.-H., Lee, E.G., Song, J.S., Kim, S.-J., 2004. The characterization and photocatalytic properties of mesoporous rutile $\mathrm{TiO} 2$ powder synthesized through self-assembly of nano crystals. Chemical Physics Letters 389, 124-128. https://doi.org/10.1016/j.cplett.2004.03.081

Ma, H., Williams, P.L., Diamond, S.A., 2013. Ecotoxicity of manufactured ZnO nanoparticles - A review. Environmental Pollution 172, 76-85. https://doi.org/10.1016/j.envpol.2012.08.011

Ma, S., Lin, D., 2012. The biophysicochemical interactions at the interfaces between nanoparticles and aquatic organisms: adsorption and internalization. Environ. Sci.: Processes Impacts 15, 145-160. https://doi.org/10.1039/C2EM30637A

Ma, S., Zhou, K., Yang, K., Lin, D., 2015. Heteroagglomeration of Oxide Nanoparticles with Algal Cells: Effects of Particle Type, lonic Strength and pH. Environ. Sci. Technol. 49, 932-939. https://doi.org/10.1021/es504730k

Manier, N., Bado-Nilles, A., Delalain, P., Aguerre-Chariol, O., Pandard, P., 2013. Ecotoxicity of nonaged and aged $\mathrm{CeO} 2$ nanomaterials towards freshwater microalgae. Environmental Pollution 180, 63-70. https://doi.org/10.1016/j.envpol.2013.04.040

Manier, N., Le Manach, S., Bado-Nilles, A., Pandard, P., 2016. Effect of two TiO2 nanoparticles on the growth of unicellular green algae using the OECD 201 test guideline: influence of the exposure system. Toxicological \& Environmental Chemistry 98, 860-876. https://doi.org/10.1080/02772248.2015.1124881

Mathé, C., Devineau, S., Aude, J.-C., Lagniel, G., Chédin, S., Legros, V., Mathon, M.-H., Renault, J.-P., Pin, S., Boulard, Y., Labarre, J., 2013. Structural Determinants for Protein adsorption/nonadsorption to Silica Surface. PLOS ONE 8, e81346. https://doi.org/10.1371/journal.pone.0081346

Monikh, F.A., Arenas-Lago, D., Porcal, P., Grillo, R., Zhang, P., Guo, Z., Vijver, M.G., Peijnenburg, W.J.G.M., 2020. Do the joint effects of size, shape and ecocorona influence the attachment and physical eco(cyto)toxicity of nanoparticles to algae? Nanotoxicology 14, 310-325. https://doi.org/10.1080/17435390.2019.1692381

Nolte, T.M., Hartmann, N.B., Kleijn, J.M., Garnæs, J., van de Meent, D., Jan Hendriks, A., Baun, A., 2017. The toxicity of plastic nanoparticles to green algae as influenced by surface modification, medium hardness and cellular adsorption. Aquatic Toxicology 183, 11-20. https://doi.org/10.1016/j.aquatox.2016.12.005

OECD, 2011. Test No. 201: Freshwater Alga and Cyanobacteria, Growth Inhibition Test.

Oukarroum, A., Bras, S., Perreault, F., Popovic, R., 2012. Inhibitory effects of silver nanoparticles in two green algae, Chlorella vulgaris and Dunaliella tertiolecta. Ecotoxicology and Environmental Safety 78, 80-85. https://doi.org/10.1016/j.ecoenv.2011.11.012

Pajerski, W., Ochonska, D., Brzychczy-Wloch, M., Indyka, P., Jarosz, M., Golda-Cepa, M., Sojka, Z., Kotarba, A., 2019. Attachment efficiency of gold nanoparticles by Gram-positive and Gramnegative bacterial strains governed by surface charges. J Nanopart Res 21, 186. https://doi.org/10.1007/s11051-019-4617-z

Pakrashi, S., Dalai, S., Prathna, T.C., Trivedi, S., Myneni, R., Raichur, A., Chandrasekaran, N., Mukherjee, A., 2013. Cytotoxicity of aluminium oxide nanoparticles towards fresh water algal isolate at low exposure concentrations. Aquatic Toxicology 132-133, 34-45. https://doi.org/10.1016/j.aquatox.2013.01.018.

Renault, S., Baudrimont, M., Mesmer-Dudons, N., Gonzalez, P., Mornet, S., Brisson, A., 2008. Impacts of gold nanoparticle exposure on two freshwater species: a phytoplanktonic alga (Scenedesmus subspicatus) and a benthic bivalve (Corbicula fluminea). Gold Bull 41, 116126. https://doi.org/10.1007/BF03216589

Ribeiro, F., Gallego-Urrea, J.A., Goodhead, R.M., Gestel, C.A.M.V., Moger, J., Soares, A.M.V.M., Loureiro, S., 2015. Uptake and elimination kinetics of silver nanoparticles and silver nitrate by 
Raphidocelis subcapitata: The influence of silver behaviour in solution. Nanotoxicology 9 , 686-695. https://doi.org/10.3109/17435390.2014.963724

Rodea-Palomares, I., Boltes, K., Fernández-Piñas, F., Leganés, F., García-Calvo, E., Santiago, J., Rosal, R., 2011. Physicochemical Characterization and Ecotoxicological Assessment of $\mathrm{CeO} 2$ Nanoparticles Using Two Aquatic Microorganisms. Toxicol Sci 119, 135-145. https://doi.org/10.1093/toxsci/kfq311

Rogers, N.J., Franklin, N.M., Apte, S.C., Batley, G.E., Angel, B.M., Lead, J.R., Baalousha, M., 2010. Physico-chemical behaviour and algal toxicity of nanoparticulate $\mathrm{CeO} 2$ in freshwater. Environ. Chem. 7, 50-60. https://doi.org/10.1071/EN09123

Rosendal Tangaa, S., Selck, H., Winther-Nielsen, M., R. Khan, F., 2016. Trophic transfer of metalbased nanoparticles in aquatic environments: a review and recommendations for future research focus. Environmental Science: Nano 3, 966-981. https://doi.org/10.1039/C5EN00280J

Sendra, M., Yeste, M.P., Gatica, J.M., Moreno-Garrido, I., Blasco, J., 2017. Homoagglomeration and heteroagglomeration of $\mathrm{TiO}_{2}$, in nanoparticle and bulk form, onto freshwater and marine microalgae. Science of The Total Environment 592, 403-411. https://doi.org/10.1016/j.scitotenv.2017.03.127

Sheng, G.-P., Yu, H.-Q., Li, X.-Y., 2010. Extracellular polymeric substances (EPS) of microbial aggregates in biological wastewater treatment systems: A review. Biotechnology Advances 28, 882-894. https://doi.org/10.1016/j.biotechadv.2010.08.001

Showalter, A.M., 1993. Structure and function of plant cell wall proteins. Plant Cell 5, 9-23.

Skjolding, L.M., Sørensen, S.N., Hartmann, N.B., Hjorth, R., Hansen, S.F., Baun, A., 2016. Aquatic Ecotoxicity Testing of Nanoparticles-The Quest To Disclose Nanoparticle Effects. Angewandte Chemie International Edition 55, 15224-15239. https://doi.org/10.1002/anie.201604964

Slaveykova, V.I., Li, M., Worms, I.A., Liu, W., 2020. When Environmental Chemistry Meets Ecotoxicology: Bioavailability of Inorganic Nanoparticles to Phytoplankton. CHIMIA International Journal for Chemistry 74, 115-121. https://doi.org/10.2533/chimia.2020.115

Sørensen, S.N., Engelbrekt, C., Lützhøft, H.-C.H., Jiménez-Lamana, J., Noori, J.S., Alatraktchi, F.A., Delgado, C.G., Slaveykova, V.I., Baun, A., 2016. A Multimethod Approach for Investigating Algal Toxicity of Platinum Nanoparticles. Environ. Sci. Technol. 50, 10635-10643. https://doi.org/10.1021/acs.est.6b01072

Suzuki, H., Toyooka, T., Ibuki, Y., 2007. Simple and Easy Method to Evaluate Uptake Potential of Nanoparticles in Mammalian Cells Using a Flow Cytometric Light Scatter Analysis. Environ. Sci. Technol. 41, 3018-3024. https://doi.org/10.1021/es0625632

Taylor, G., Baird, D.J., Soares, A.M.V.M., 1998. Surface binding of contaminants by algae: Consequences for lethal toxicity and feeding to Daphnia magna straus. Environmental Toxicology and Chemistry 17, 412-419. https://doi.org/10.1002/etc.5620170310

Vallotton, P., Angel, B., Mccall, M., Osmond, M., Kirby, J., 2015. Imaging nanoparticle-algae interactions in three dimensions using Cytoviva microscopy. Journal of Microscopy 257, 166169. https://doi.org/10.1111/jmi.12199

Valsesia, A., Desmet, C., Ojea-Jiménez, I., Oddo, A., Capomaccio, R., Rossi, F., Colpo, P., 2018. Direct quantification of nanoparticle surface hydrophobicity. Communications Chemistry 1, 53. https://doi.org/10.1038/s42004-018-0054-7

Van Hoecke, K., De Schamphelaere, K.A.C., Van der Meeren, P., Lcucas, S., Janssen, C.R., 2008. Ecotoxicity of silica nanoparticles to the green alga pseudokirchneriella subcapitata: Importance of surface area. Environmental Toxicology and Chemistry 27, 1948-1957.

Viana, M.M., Soares, V.F., Mohallem, N.D.S., 2010. Synthesis and characterization of TiO2 nanoparticles. Ceramics International 36, 2047-2053.

https://doi.org/10.1016/j.ceramint.2010.04.006 
Wang, F., Guan, W., Xu, L., Ding, Z., Ma, H., Ma, A., Terry, N., 2019. Effects of Nanoparticles on Algae: Adsorption, Distribution, Ecotoxicity and Fate. Applied Sciences 9, 1534. https://doi.org/10.3390/app9081534

Wang, Y., Zhu, X., Lao, Y., Lv, X., Tao, Y., Huang, B., Wang, J., Zhou, J., Cai, Z., 2016. TiO2 nanoparticles in the marine environment: Physical effects responsible for the toxicity on algae Phaeodactylum tricornutum. Science of The Total Environment 565, 818-826. https://doi.org/10.1016/j.scitotenv.2016.03.164

Zhao, J., Cao, X., Liu, X., Wang, Z., Zhang, C., White, J.C., Xing, B., 2016. Interactions of CuO nanoparticles with the algae Chlorella pyrenoidosa: adhesion, uptake, and toxicity. Nanotoxicology 10, 1297-1305. https://doi.org/10.1080/17435390.2016.1206149

Zhou, K., Hu, Y., Zhang, L., Yang, K., Lin, D., 2016. The role of exopolymeric substances in the bioaccumulation and toxicity of Ag nanoparticles to algae. Scientific Reports 6, 1-11. https://doi.org/10.1038/srep32998

Zucker, R.M., Massaro, E.J., Sanders, K.M., Degn, L.L., Boyes, W.K., 2010. Detection of TiO2 nanoparticles in cells by flow cytometry. Cytometry Part A 77A, 677-685.

https://doi.org/10.1002/cyto.a.20927 


\section{Captions}

Figure 1. Flow cytometry analysis schema. Left: cytogram of the algae control population. Right: cytogram of a typical population of algae + NMs with a percentage of the population showing higer complexity

Figure 2. Dose-response curves for the three tested algae 1) R. subcapitata, 2) D. subspicatus and 3) C. vulgaris at the tested concentrations going from 0.1 to $50 \mathrm{mg} / \mathrm{L}$. Graphics labeled A) show the TiO2 NMs (NM100, NM101, NM102, NM103, NM104 and NM105), B) show the SiO2 NMs (NM200, NM202 and NM204), C) the ZnO NMs (NM110) and D) the $\mathrm{CeO} 2 \mathrm{NMs}(\mathrm{CeO} 2<25$ and $\mathrm{CeO} 2<10)$.

Figure 3. Percentage of modified Raphidocelis subcapitata population at $7,5 \mathrm{mg} / \mathrm{L}$ of each tested NMs divided by composition. Letters indicates the statistical significantly different results inside each group of the same NMs composition.

Figure 4. Correlation between the measured zeta potential of NMs in algae media and the percentage of modified algae at an intermediate effect concentration. A) R. subcapitata at $5 \mathrm{mg} / \mathrm{L}$; b) D. subspicatus at $25 \mathrm{mg} / \mathrm{L}$ and c) C.vulgaris at $5 \mathrm{mg} / \mathrm{L}$. the surface charge of NMs. The red dotted lines show the tendencies.

Figure 5. Optical microscopy images at 40x objective of the algae-NMs contact test at $50 \mathrm{mg} / \mathrm{L}$ of NMs and 15 minutes contact with R. subcapitata. Blue arrows show free algae, red arrows show single algae surrounded by NMs and black arrows show heteroagglomerates formed by algae and NMs. 

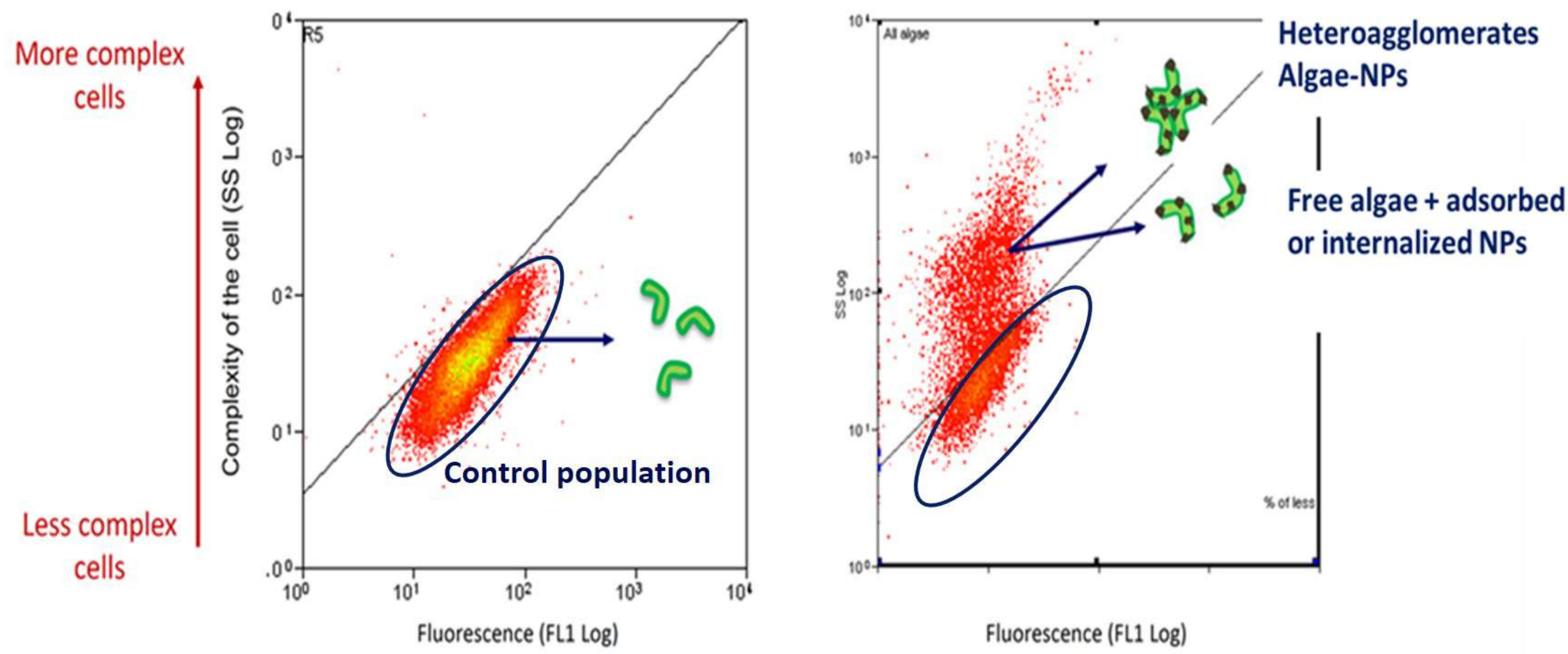


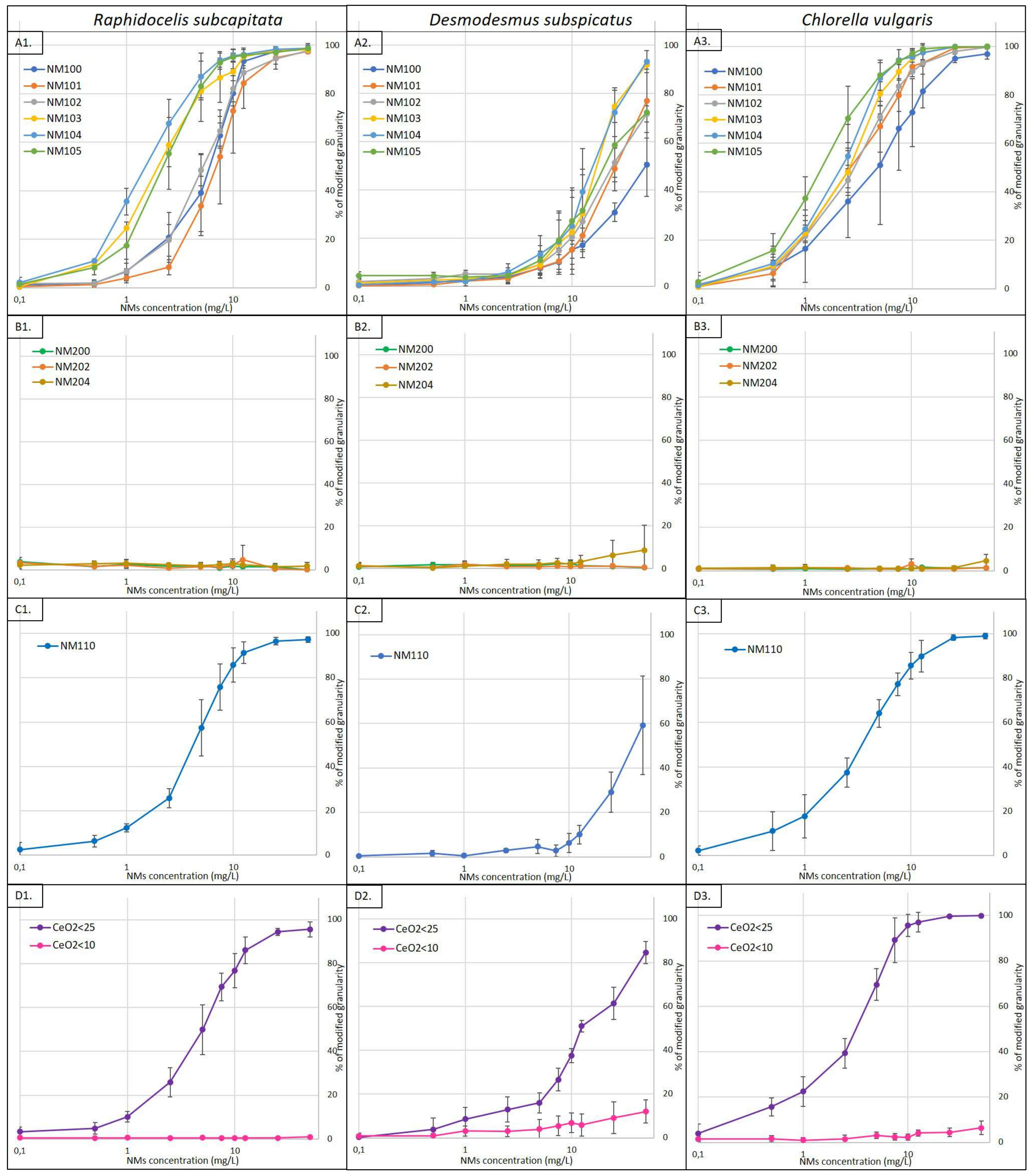


Raphidocelis subcapitata $7.5 \mathrm{mg} / \mathrm{L}$

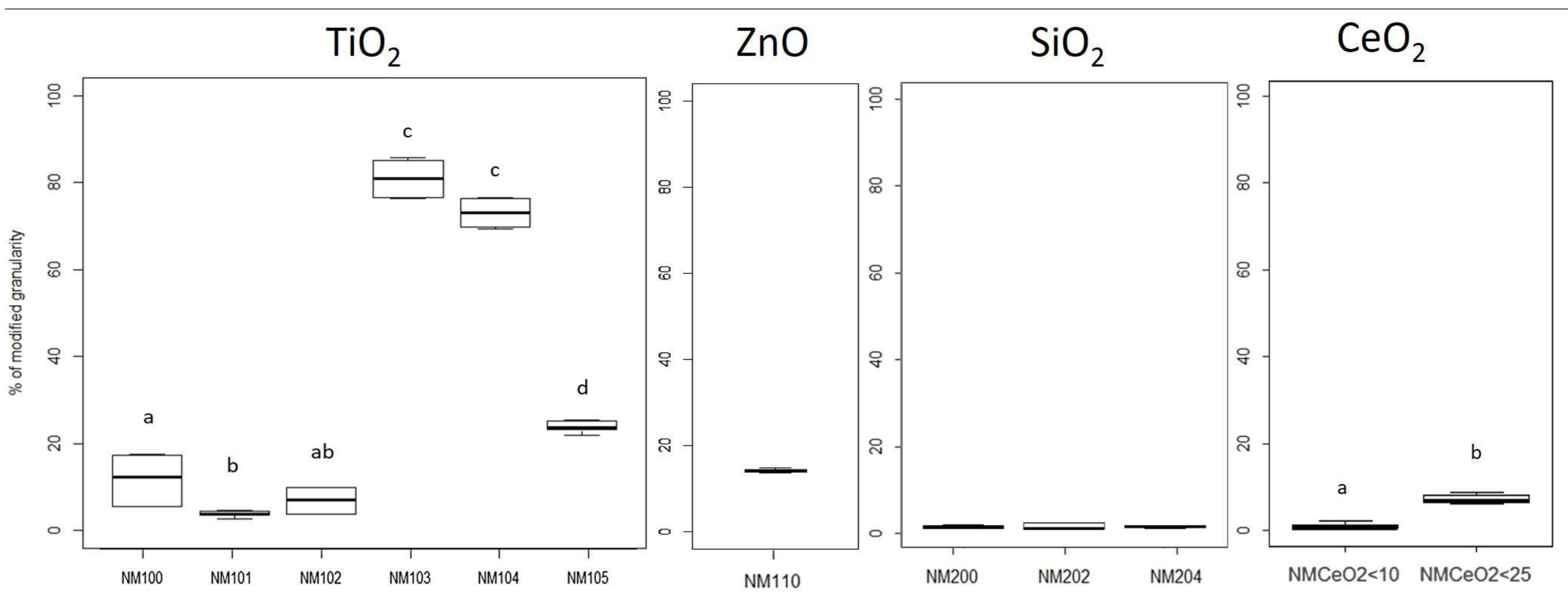




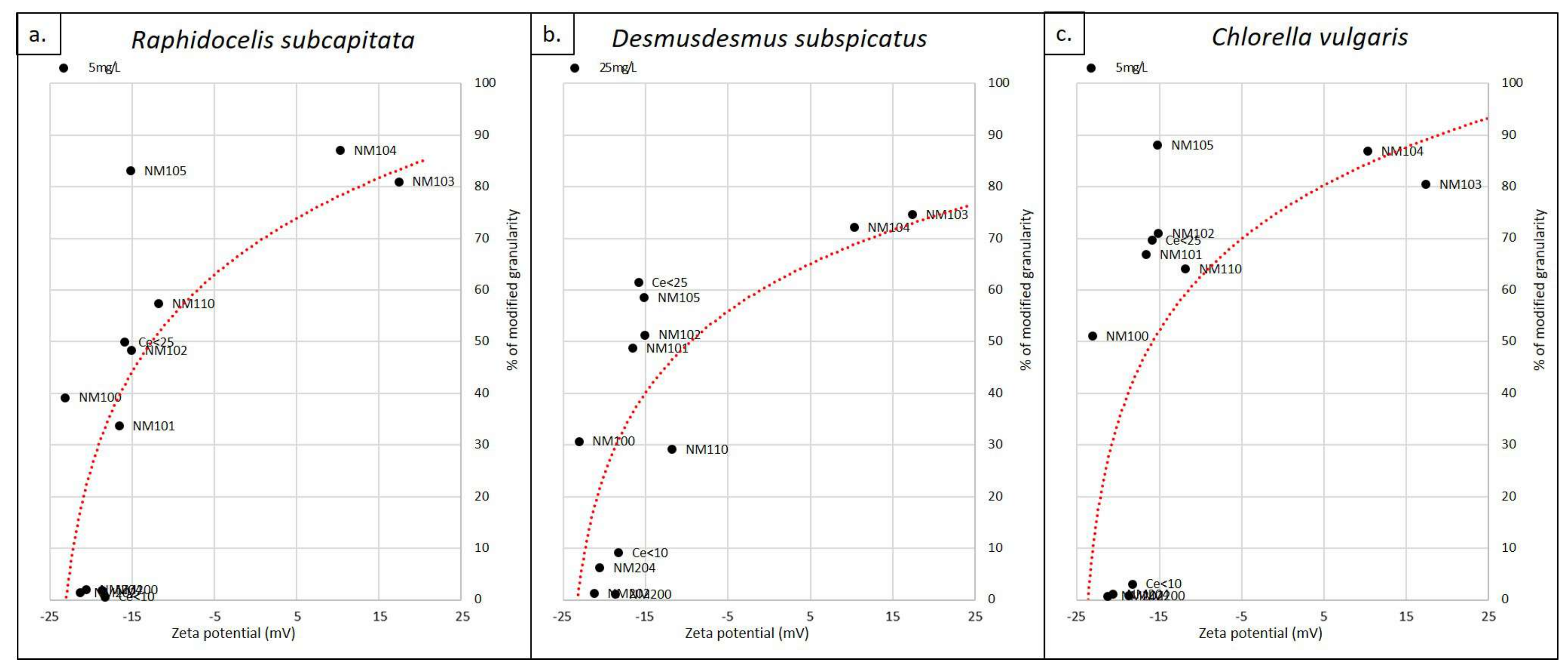




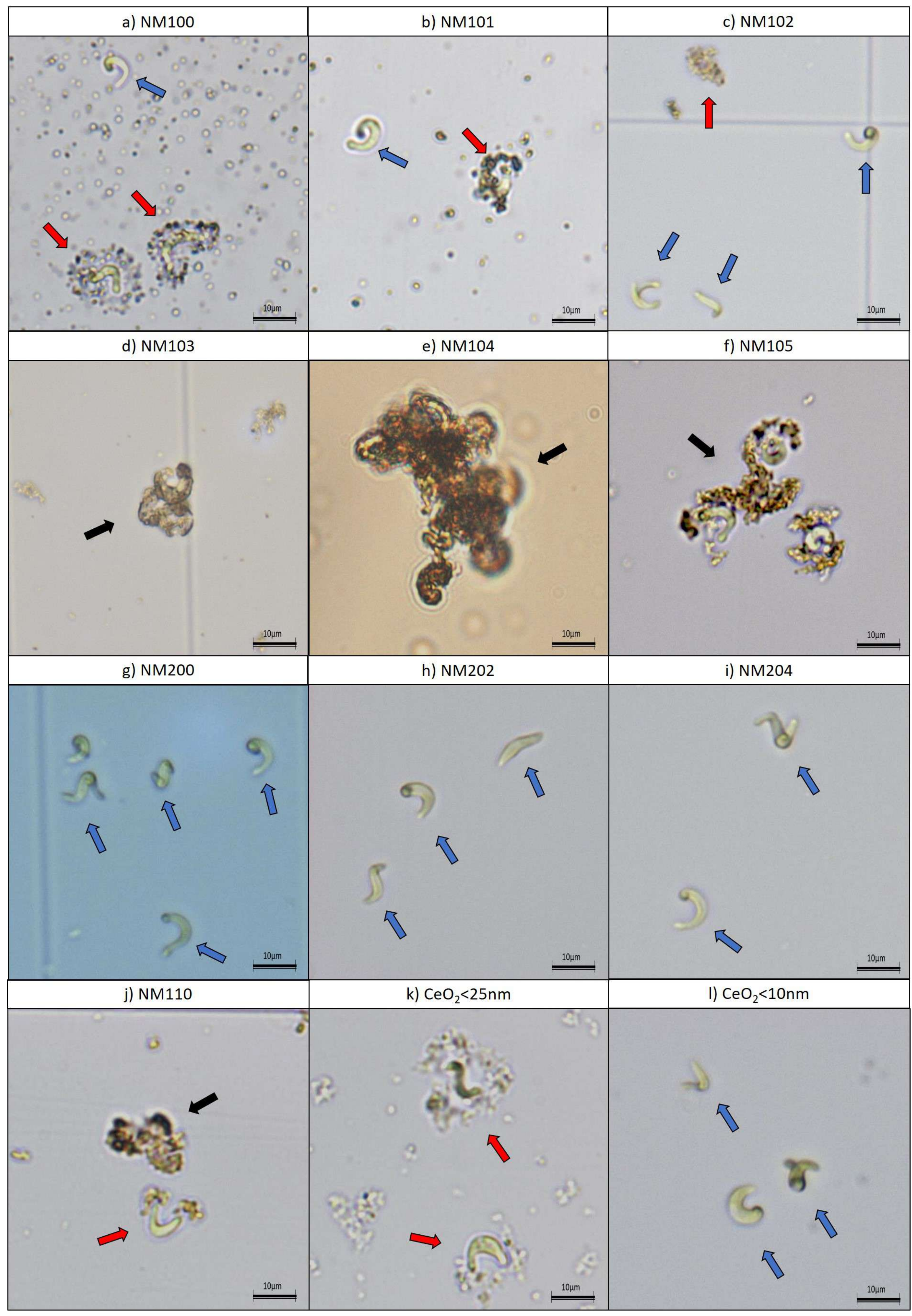

